\title{
Routine Childhood Immunisation
}

\section{Is it Worth It?}

\author{
S.P. Conway ${ }^{1}$ and Brenda Leese ${ }^{2}$ \\ 1 Department of Infectious Diseases, Seacroft Hospital and University Department of Paediatrics, and Child \\ Health, St James's University Hospital, Leeds, England \\ 2 Centre for Health Economics, University of York, York, England
}

\section{Introduction}

Every child has the right to protection, where that protection exists, against infectious agents which can maim or kill. Protection of the totally dependent infants is for society to encourage, and it is for parents and all medical persons involved with children to see this through. Attempts to prevent childhood infectious diseases began over a century ago with smallpox, and only smallpox has been eradicated. Other half-forgotten diseases wait only for a fall in immunisation uptake to remind us of their devastating power to damage and kill.

The World Health Organization target of $90 \%$ uptake of primary immunisation by 1990 has been achieved in England for all of the childhood diseases except pertussis, which reached $88 \%$ by 1991 (White et al. 1992). However, this overall figure conceals less successful rates in some health districts, usually deprived inner city areas. The introduction in 1990 of target payments to general practitioners for achieving specific immunisation uptake rates, as part of their new contract (Department of Health 1989), together with a change in immunisation schedules (Department of Health 1990), have been successful in helping to improve uptake rates. However, the cost of achieving the last 5 to $10 \%$ of uptakes in some inner city areas is particularly high, and may outweigh the health benefits. The targets may also act as disincentives when general practitioners find that the effort of reaching the last few patients outweighs the financial rewards for reaching the targets (Leese \& Bosanquet 1992).

Other factors which have an effect on immunisation uptake rates include the perceptions of parents about the possible severity of a disease. If parents have little experience of a disease, e.g. diphtheria, or regard it as of little consequence, e.g. measles, they will be less likely to present their children for immunisation. This becomes more of a problem for a vaccine, such as that for measles, which is given in the second year of life when regular attendance at child health clinics has ceased. However, the combination of measles with mumps and rubella in the MMR vaccine, available since 1988 , may have been one factor in the improved uptake rates for this vaccine, which reached $90 \%$ in England in 1991 (Leese \& Bosanquet 1992).

Compliance is particularly difficult to achieve in inner city areas, partly because of the high proportion of families in temporary accommodation who may not be registered with a GP. Other social factors such as a lack of family support and reliance on public transport may all combine to discourage vaccination for diseases perceived to be of little significance. Adverse publicity about some vaccines has not helped this situation, but local health education campaigns can be effective (Cates 1990).

Immunisation protects not only those immun- 
ised, but also those not immunised within a community, by blocking the transmission of a disease within what is effectively a smaller susceptible population. This effect is known as 'herd immunity'. In an excellent analysis of herd immunity and its effect, Anderson and May (1990) list the critical vaccination coverage necessary to block transmission of specific diseases for which immunisation is available. For polio this is as low as $85 \%$, but for measles and pertussis it is up to $95 \%$, and for mumps 90 to $92 \%$. This means that, for example, $95 \%$ of the population must be immunised against measles to prevent any more cases developing. Continued vigilance is therefore necessary, not only to achieve high compliance rates, but also, once achieved, to ensure these high levels are maintained.

To assess whether an immunisation programme is cost effective, it is necessary to examine the costs of implementing the programme, which might include the employment of additional staff, the cost of the vaccine itself and the cost of treating any complications, together with any hospitalisation costs. The probability of complications should also be taken into account. The benefits include a reduction in costs due to fewer cases and complications, and reduced mortality. However, once the incidence of the disease has reached very low levels, the costs of pursuing the last few unimmunised patients may exceed the benefits in terms of numbers of cases averted. Opportunity costs, or health outcomes foregone elsewhere by committing resources to one particular programme, become increasingly important as incidence decreases. It is essential, nevertheless, to ensure that, once maintained, herd immunity is not lost, or a disease could return.

Childhood immunisation programmes offer protection against diphtheria, tetanus, whooping cough (also known as diphtheria-tetanus-pertussis or DTP in a combined form), poliomyelitis, measles, mumps, rubella, Haemophilus influenzae type $\mathrm{B}$, and tuberculosis. The arguments for immunising against each of these are considered. Unfortunately, there have been few studies, particularly in the UK, on the costs and benefits of immunisation.

\section{Childhood Immunisation Programmes}

\subsection{Pertussis}

The greatest controversy has surrounded the pertussis component of the triple vaccine (DTP), although the need for protection against Bordetella pertussis itself is incontrovertible. In the early part of this century, pertussis was a major cause of childhood mortality and case numbers worldwide can still total 60 million annually with more than half a million deaths. The greatest incidence is in developing countries where immunisation uptake is low and the majority of cases probably go unreported (Muller et al. 1986).

Once established, whooping cough runs a protracted and distressing course. Parental fears remain as intense as in 1661 when Mary Baker wrote to her husband, 'I am in sad condition for my pore children who are all so trobled with the chincough that I am afraid it will kill them... They have such fitts that it stopes theare wind, and puts me in such frits and feares that I am not myselfe' (Lambert 1985). The greatest mortality from pertussis occurs in children less than 6 months old (Sako et al. 1945). Admission to hospital is common in the lower socioeconomic classes who can least afford either the time off work to stay with or visit their child, or the cost of daily travel to and from the hospital. Routine home life is severely disrupted for a long time and everyone in the household suffers (Conway \& Phillips 1989; Lambert 1985).

The whole-cell vaccine has been available since the 1950s and achieved an uptake rate in England and Wales of $81 \%$ in 1969 . Controlled trials in the US and the UK have proven its efficacy (Bell 1948; Medical Research Council 1959), which lies between 80 and 90\% (Palmer 1991). In cases where vaccination is followed by pertussis infection, the illness tends to follow a milder course (Expanded Programme on Immunization 1984), and even incomplete immunisation may offer some protection against a fatal outcome (Morley et al. 1966). After adoption of the whole-cell vaccine in 1957, through to 1972 , epidemic peaks and inter-epidemic troughs of whooping cough incidence decreased progressively in England and Wales (Begg 1987). The 1972 
notification figure of 2069 was the lowest recorded. In 1974, media focused on a report of 36 cases of severe neurological illness following pertussis immunisation and public confidence in the safety of the vaccine was destroyed (Kulenkampff et al. 1974). Uptake rates fell to $31 \%$ in 1978 . Notifications of the disease reached 65956 in the same year, the highest figure recorded since 1956, and 36 patients died. Further epidemics followed in 198183 and 1985-87.

In Japan, the vaccine was withdrawn in the early 1970s after a report of 2 deaths following DTP immunisation and a pertussis epidemic ensued in 1979 with 41 deaths (Noble et al. 1987). The figures clearly show that the accelerated fall in notification after the mid-1950s was largely due to the impact of the vaccine and not merely a reflection of improved social conditions. Efforts directed at renewing parents' confidence achieved an acceptance rate of $65 \%$ in 1985 and the expected 1986 epidemic did not develop (Maxwell 1989). By 1991 uptake rates reached $88 \%$ (White et al. 1992).

The safety of the pertussis vaccine has been seriously questioned but analyses of the literature give no support to the existence of a vaccine-associated encephalopathic syndrome (Golden 1990), or of a causal relationship with an acute encephalopathy or with any permanent neurological sequelae (Cody 1981; Golden 1990; Long et al. 1990). Neurological events temporally associated with pertussis immunisation are likely to be chance associations of such events known to occur in the target age group (Golden 1990; Griffith 1989; Wentz \& Marcuse 1991). The conclusions of Kulenkampff and associates and those of the National Childhood Encephalopathy Study (Alderslade et al. 1981), have been criticised for selection bias (Wentz \& Marcuse 1991). The latter study was also criticised for inclusion of cases with other potential aetiology, and for unsatisfactory assessments of developmental delay (Griffith 1989). However, the implementation in the US of compensation for vaccine damage under the National Childhood Vaccine Injury Act has had the effect of markedly increasing the costs of the vaccines (Clayton \& Hickson 1990; Smith 1988). The English courts have stated that on the balance of probability, there is not enough evidence to conclude that pertussis vaccine causes permanent brain damage in young children (Wentz 1991). However, recent success in the Irish courts may reopen the controversy in the UK (Dyer 1992).

Although no serious adverse effects can be attributed to the whole cell pertussis vaccine, it is responsible for most of the minor adverse effects of the DTP triple immunisation (Cody et al. 1981). Progress in the identification and isolation of the biologically active components of pertussis cells, and the antigens important for the induction of an effective immune response, have led to the development of acellular pertussis vaccines. These appear to remain immunogenic whilst provoking fewer local adverse effects and less fever (Blumberg et al. 1991; Krantz et al. 1990), and may increase parental acceptance of the childhood immunisation programme. The acellular vaccine is at present the subject of government-directed trials in the UK.

There have been no cost-effectiveness studies of pertussis immunisation in the UK, although its clinical effectiveness is not now in dispute. A study in the US showed a benefit-to-cost ratio of $11: 1$ (Hinman \& Kaplan 1984), and Velimirovic (1991) in a detailed review of the social, economic and psychological impacts of childhood diseases quoted a ratio of $3: 1$ for pertussis. Such benefit-to-cost ratios take into account the costs of treating cases of a disease together with its complications, balanced against the benefits (or averted costs) of implementing immunisation programmes with their associated costs. If the cost of the vaccination programme together with the cost of treating a reduced number of cases of the disease are lower than the costs of treating the disease in an unvaccinated population, then the benefits (in monetary terms) will outweigh the costs, and a positive benefit-tocost ratio will result.

\subsection{Diphtheria}

The case for routine childhood immunisation against diphtheria, tetanus and poliomyelitis is less controversial. Diphtheria immunisation was intro- 
duced into England and Wales in 1940 when the annual notification and death rates were running at over 46000 and over 2000 , respectively. It was the premier cause of death in 4- to 10-year-old children. In the tenth year of mass immunisation only 962 cases were notified and in 1979 there were none. The infection is spread among humans by droplet infection only and could theoretically be eradicated. However, until such time, it remains a continuing hazard. Cutaneous diphtheria in immigrant families returning from the tropics can be a hidden source of infection which may spread rapidly among contacts. Those without immunity cannot rely on herd immunity for protection (Bowler et al. 1988).

\subsection{Tetanus}

Routine tetanus immunisation began in England and Wales in the early 1960s. As a result the infection has virtually disappeared in children. It must be kept in mind that Clostridium tetani is a ubiquitous organism and that even a trivial injury may provide it with an adequate point of entry. It is therefore essential that immunisation rates remain high in the community. As with diphtheria, treatment is mostly supportive and consists of an attempt to counteract the effects of the toxin. There is no 'cure'. Both diphtheria and tetanus toxoid vaccines are safe and minor reactions which may occur in up to $20 \%$ of children have no long term consequences (Cody et al. 1981; Jacobs et al. 1982).

\subsection{Poliomyelitis}

The introduction of the inactivated Salk poliomyelitis vaccine to England and Wales in 1956 was followed by a rapid decline in the notification rate. Routine vaccination in the UK is now done with the live attenuated Sabin strain which has the added advantage of spreading the vaccine to close, unimmunised contacts who would otherwise be unprotected. Treatment of established disease is again supportive and not curative and potential complications are severe. The vaccine is effective and has only one important disadvantage in that it may itself cause paralysis in 1 per million recipients, with a similar risk for non-immune contacts of vaccinees. A recent poliomyelitis outbreak in Israel (Anon. 1988) highlighted the continuing risk of infection and sparked discussion about the different merits of inactivated and live attenuated vaccines (Slater et al. 1990). There were no dissenters, however, from the consensus view that effective immunisation is essential. High levels of immunity must be maintained since, when immunisation levels fall, outbreaks of the disease are likely to recur.

Diphtheria, tetanus and poliomyelitis are now rare diseases in the UK, and studies of the costs and benefits of vaccination programmes have not been reported, and, in any case, are more difficult to carry out as diseases become rarer. However, whatever the costs of the vaccination programme, it would be inopportune to discontinue it, because of the inevitable resurgence of the diseases, possibly being imported from abroad (Nicoll et al. 1989). Any resulting epidemic would be costly to treat. Vaccination against these diseases is an undoubted success story in the UK.

The new vaccination schedule introduced recently into the UK (Department of Health 1990) involving accelerated immunisation at ages 2 to 4 months for diphtheria, tetanus and poliomyelitis has been shown in a controlled study of 222 children immunised under the accelerated and standard schedules to cause fewer reactions than when given to older children (Ramsey et al. 1992).

\subsection{Measles}

There is a persistent misapprehension amongst the general population that measles is a childhood illness of no consequence (Conway \& Phillips 1989), yet for every 1000 notifications there are 0.2 deaths, 10 admissions, 10 neurological and 40 respiratory complications. Even in mild nonhospitalised cases there is significant misery for both child and family (Barry 1988). The scale of devastation to children's health before immunisation can be appreciated by assimilation of the fact that there were 460407 cases notified in England and Wales in 1967, the year 
before the onset of mass immunisation. Approximately 800000 children were vaccinated in the first year of the immunisation programme, an uptake rate sufficient to prevent the expected 1969 peak (Anon. 1990). Vaccine efficacy is about $95 \%$ (King et al. 1991) but uptake has been poor until very recently. Only 47 to $55 \%$ were vaccinated before their third birthday from 1971 to 1981 , allowing free and wide circulation of the measles virus in the community. From 1980 to 1985 , the annual average admission and death rates for measles were 2500 and 15 , respectively. The 1986 notification rates per million total population were 1599 in the UK and 27 in the US. The latter had achieved 97\% vaccination before school entry, and the former had not (Begg 1987). Six children died in the first half of the 1988 epidemic in England and Wales and 5 of them were old enough to have been vaccinated (Begg 1988). By 1991, 90\% of children in England had been vaccinated against measles by 2 years of age (White et al. 1992). The 1990 notification and general practitioner consultation rates were lower than ever before (Anon. 1990).

The unimmunised are always at risk, as exemplified during the 1989 US epidemic, which was largely a result of the Mexican epidemic on the American border (Brunnell 1990). The 2 age groups affected were the unimmunised preschool children who suffered the most severe disease and all of the deaths, and the mostly immunised 15- to 19-yearolds. The US National Vaccine Advisory Committee analysed the reasons for the outbreak and, as well as making several recommendations related to service provision, which raised concerns about the primary healthcare system, endorsed the implementation of the 2-dose measles vaccine strategy (National Vaccine Advisory Committee 1991). Others have raised the issue of the increased cost of vaccines and lack of funding as one which could have serious consequences for vaccination coverage in the US (Nassau 1992; Sloan 1992). Similarly, in a measles outbreak in a London school, the highest attack rate was in the class with the lowest immunisation rate (Morgan 1986). The conclusion from the study of these and other epidemics is that a low vaccination rate among preschool children, particularly in minority groups in inner city areas, is the most important causal factor in the spread of the infection (King et al. 1991). Acute infection results from failure to vaccinate rather than from vaccine failure. It is important to capture nonresponders and those missed at preschool age. The question is not, therefore, whether childhood immunisation against measles is worthwhile, but whether we should offer a booster vaccination to the older child. The answer is again affirmative. American authorities further recommend early vaccination at 12 months in high risk areas, and as early as 6 months during a measles outbreak (American Academy of Paediatrics 1989). A strategy of booster vaccination of older children has not been implemented in the UK.

There have been several studies of the costeffectiveness of measles vaccination in the US, usually prompted by increased numbers of cases either locally or nationally (Mast et al. 1990; Sellick et al. 1992) but few such studies have been reported in the UK. Mast et al. (1990) assessed which school population subgroups should be revaccinated after a local measles outbreak, and calculated the hypothetical cost per case prevented using different strategies. The strategies were to revaccinate only those previously vaccinated before the age of 12 months, those who had been vaccinated before the age of 15 months, and revaccination of all students. This study endorsed the 2dose vaccination schedule, which was not fully implemented at that time. Sellick et al. (1992) examined the cost-effectiveness of strategies to ensure that hospital employees maintain immunity to measles, because they are at risk from patients with the disease. The study took place in a US teaching hospital where it was found that screening for immunity followed by immunisation as required was less costly than immunising all potentially susceptible employees, although the authors were aware that this method may not be applicable in other settings. Savings of US\$6.05 per established hospital employee were recorded.

A benefit-to-cost ratio of $12: 1$ in the US for vaccination against measles was reported by Nicoll et al. (1989). This result should be compared with 
a study in Israel, which calculated benefit-to-cost ratios of from $4.53: 1$ to $9.59: 1$, depending upon locality and differing incidences, for the adoption of the 2-dose strategy referred to above, which appeared to be economically advantageous (Ginsberg \& Tulchinsky 1990). The methods of calculating the costs of the vaccination programme and treating adverse effects, the costs of treating cases of measles and its complications including home visits, medication, hospitalisation and time lost from work for adults or parents, and the benefits (or averted costs) after immunisation in terms of treating fewer cases of measles and its complications, were all well documented in this detailed paper. Velimirovic (1991) quoted ranges of benefit-to-cost ratios from $4: 1$ to $10: 1$ for different measles immunisation programmes.

As far as the UK is concerned, economic analyses have been noticeably absent and are urgently needed, There has been much recent interest in measles, probably prompted by the introduction of the measles, mumps, rubella (MMR) vaccine in 1988 , and the fact that until recently, uptake rates were low (Leese \& Bosanquet 1992). A study in Northern Ireland, reported in 1984, determined costs for measles immunisation and treatment of hospitalised cases, and concluded that an effective vaccination policy would save resources as well as preventing disease (McConnell \& Tohani 1984).

\subsection{Mumps}

The postpubertal male fears the potential sterilising effects of mumps infection, but the adult population in general has been unaware of the much greater potential of the mumps virus to damage young children. With no immunisation, mumps epidemics occur at 3-yearly intervals in England and Wales. Over 1000 children with mumps were admitted to hospital in 1988. Acute infection is complicated by mumps meningitis in 1 in every 400 cases. Other complications include irreversible sensorineural deafness. Since the introduction of the MMR vaccine in 1988 , there has been a $79 \%$ decrease in notifications and successful interruption of the epidemic cycle, similar to experience in
Canada and the US (McDonald et al. 1989). The prospects for elimination of the disease are promising. The vaccine is not associated with any serious sequelae (McDonald et al. 1989). Benefit-tocost ratios for different mumps immunisation programmes of $2: 1$ to $7: 1$ have been reported (Velimirovic 1991).

\subsection{Rubella}

The third arm of the trivalent MMR vaccine is directed at eradicating the congenital rubella syndrome (CRS), recognised since its description in 1941 (Gregg 1941). Infants born following maternal infection in pregnancy may continue to excrete the virus and pose an ongoing epidemic risk (Lindquist et al. 1965).

Without an effective immunisation policy for women in their childbearing years, the fetus is at significant risk in every rubella epidemic (Owens \& Espino 1989). Immunising the susceptible female, however, may not be sufficient safeguard. The UK rubella immunisation policy, initially directed at schoolgirls and susceptible women, aimed to eliminate rubella in pregnancy. Although the proportion of susceptible antenatal women fell to $2 \%$, the policy was not a success and there remained a deficit of rubella immunity in women of childbearing age. In England and Wales in 1986-87, 372 pregnant women contracted confirmed rubella infection, nearly half of which occurred in the first trimester of pregnancy. Notification of CRS continued at about 20 cases per year. Oversight was given as the reason for failure to vaccinate these women at risk. Susceptible women who were pregnant when tested were less likely to receive the vaccine post partum than those who were not pregnant (Berkeley et al. 1991). They would thus be at risk in any future pregnancy of contracting rubella from their own older children or from other children (Miller et al. 1991). Targeting the vaccine only at schoolgirls and women did not eliminate the CRS so long as free circulation of the wild virus amongst children continued.

In 1986 in England and Wales, $86 \%$ of schoolgirls had received rubella immunisation by 14 years 
of age. There had been no change in uptake since 1984, suggesting that schoolgirl vaccination had reached a plateau below the $95 \%$ target. The clear conclusion from the above data was that the immunisation programme had to be extended to the young children and in 1988 protection against rubella was offered to all 1- to 2-year-olds and preschool children as part of the MMR initiative. Although 1990 should have been an epidemic year, the numbers of confirmed cases in children and pregnant women were the lowest annual figures recorded. The previous trend for a greater rubella incidence in susceptible parous women compared with nulliparous women was reversed in 1989, suggesting that the MMR programme was already effective in decreasing the exposure of pregnant women to children with rubella (Miller et al. 1991).

Selective vaccination alone was also believed to be an important factor in the emerging risk of rubella reinfection as a significant cause of CRS (Cusi et al. 1990; Miller 1990; Miller et al. 1991). The MMR programme should effectively stifle this threat.

In common with measles, a 2-dose strategy might be necessary for mumps and rubella, since the possibility exists that immunity might wane and adults might become susceptible to these diseases without a second dose. Indeed, in Finland, a second MMR dose is given at school entry, and in Sweden at 12 years of age. A similar strategy has been recommended in the US (Isaacs \& Menser 1990). This would have consequences not only for increased costs of implementing the immunisation policy, but also increased benefit in terms of disease prevention.

The MMR vaccination programme in the UK has yet to undergo cost-effectiveness evaluation. One US study reported a benefit-to-cost ratio of $8: 1$ for rubella (Nicoll et al. 1989). In another review, Velimirovic (1991) quoted ratios ranging from $6: 1$ to $20: 1$ for rubella.

\section{$2.8 \mathrm{H}$. Influenzae type B}

The cumulative risk of invasive $H$. influenzae type $\mathrm{B}(\mathrm{Hib})$ disease for UK children by their fifth birthday was 1 in 600 in the pre-vaccination era
(Booy et al. 1992). Infection may show itself as meningitis, cellulitis, epiglotitis, pericarditis, arthritis or pneumonitis. About $56 \%$ of invasive $H$. influenzae infections result in meningitis (Nazareth et al. 1992). Mortality is around $3.5 \%, 6 \%$ of survivors suffer from deafness and a further $4 \%$ other permanent neurological sequelae, e.g. motor incoordination, deficits in intelligence, and learning difficulties (Cartwright 1992). The Hib vaccines are the safest ever proposed for routine use and can prevent more than $90 \%$ of invasive disease (Booy et al. 1999). Their administration is compatible with established immunisation schedules and therefore simple and economic in terms of healthcare professionals' time. The protein-conjugate vaccines stimulate an effective immune response in infants those most susceptible to invasive Hib disease. Immunisation at 2, 3 and 4 months of age is expected to prevent most cases of Hib disease in children in the UK (Booy et al. 1992).

\subsection{Tuberculosis}

Tuberculosis differs from the diseases described so far, in that the current UK policy is to vaccinate school children aged 10 to 13 years, compared with other countries in which newborn are routinely vaccinated (Leese \& Bosanquet 1992). Bacillus Calmette-Guérin (BCG) vaccination against tuberculosis in the UK began in 1948 and uptake rates have been consistently high ( $96 \%$ in 1987-88). In spite of such high rates, there were 5432 notifications and 443 deaths in 1989 in England and Wales, perhaps reflecting the vaccine's variable efficacy $(60$ to $80 \%$ ), and the fact that it is no longer offered to all British schoolchildren.

Discontinuation of the vaccination scheme has been considered because the disease no longer poses the threat it once did, it is treatable, and is in decline irrespective of vaccination. It has been estimated that if the immunisation scheme were discontinued, there would be a slowing of the decline in notifications initially, which would not be epidemiologically disastrous. In effect, the costs of the vaccination scheme may exceed the benefits. However, a benefit-to-cost ratio of less than 1 does not 
necessarily mean that a scheme should be stopped, and the disease could return. Moreover, it is not known what effect the increase in human immunodeficiency virus (HIV) cases may have on the incidence of tuberculosis (Springett \& Sutherland 1990). HIV infection has also highlighted the problem of drug resistance in tuberculosis infection (Edlin et al. 1992). This may have a positive effect on BCG vaccination strategies. There are no guarantees that drug-resistant mycobacteria will remain contained within easily defined high-risk patient groups.

\section{Conclusion}

The extensive literature on childhood immunisation confirms its efficacy and safety, but the distinct lack of economic analyses of vaccination programmes should be addressed. It is clear that these programmes have had an immense positive impact on child health but have not yet eradicated the target diseases. While our attention is excited by new vaccines, we must remain vigilant in ensuring that as many children as possible continue to receive protection against the infections discussed above. The enemies of our childrens' health are contained but not defeated.

\section{References}

Alderslade R, Bellman MH, Rawson NSB, Ross EM. The National Childhood Encephalopathy Study. In Whooping cough: reports from the Committee on Safety of Medicines and the Joint Committee on Vaccination and Immunization, pp. 79154, Department of Health and Social Security, Her Majesty's Stationery Office, London, 1981

American Academy of Pediatrics. Measles: reassessment of the current immunization policy. Pediatrics 84: 1110-1113, 1989

Anderson RM, May RM. Immunisation and herd immunity. In Moxon ER (Ed.) Modern vaccines: Current practice and new approaches, Edward Arnold, London, 1990

Anonymous. Diptheria: West Midlands. Communicable Disease Report 42: 1, 1986

Anonymous. Paralytic poliomyelitis - Israel. Communicable Disease Report 40: 1, 1988

Anonymous. Measles surveillance 1960-89: England and Wales. Communicable Disease Report 25: 1, 1990

Anonymous. SSPE in the developing world. Lancet 336: 600, 1990

Barrett CD, Mclean W, Molner JG, Timm EA, Weiss CF. Multiple antigen immunisation of infants against poliomyelitis, diphtheria, pertussis and antigen immunisation of infants against poliomyelitis, diphtheria, pertussis and tetanus. Pediatrics: $720-736,1962$
Barry J. The misery of measles for patients and their families. Communicable Disease Report 46: 3, 1988

Begg NT. Childhood vaccine-preventable disease. Public Health Laboratory Service Microbiology Digest 4: 38-39, 1987

Begg NT. Six deaths from measles. Lancet 1: 1451, 1988

Bell JA. Pertussis immunisation: use of two doses of alum-precipitated mixtures of diphtheria toxoid and pertussis vaccine. Journal of the American Medical Association 137: 1276-1281, 1948

Berkeley MIKB, Moffat MAJ, Russell D. Surveillance of antibody virus in Grampian: closing the immunity gap. British Medical Journal 303: 1174-1176, 1991

Blumberg DA, Mink C, Cherry JD, Johnson C, Garber R, et al. Comparison of acellular and whole-cell pertussis component diphtheria-tetanus-pertussis vaccines in infants. Journal of Pediatrics 119: 194-204, 1991

Booy R, Taylor SA, Dobson SRM, Isaacs D, Sleight Cr. Immunogenicity and safety of PRP-T conjugate vaccine given according to the British accelerated immunisation schedule. Archives of Disease in Childhood 67: 475-478, 1992

Bowler ICJ, Mandal BK, Schlect B, Riordan T. Diphtheria - the continuing hazard. Archives of Disease in Childhood 63: 194, 1988

Brunnell PA. Measles one more time. Pediatrics 86: 474-477, 1990

Cartwright KAV. Vaccination against Haemophilus influenzae b disease. British Medical Journal 305: 485-486, 1992

Cates CJ. A handout about tetanus immunisation: influence on immunisation rate in general practice. British Medical Journal 300: 789-790, 1990

Clayton EW, Hickson GB. Compensation under the National Childhood Vaccine Injury Act. Journal of Pediatrics 116: 508513,1990

Cody CL, Baraff LJ, Cherry JD, Marcy SM, Manclark CR. Nature and rates of adverse reactions associated with DTP and DT immunizations in infants and children. Pediatrics 68: 650-660, 1981

Conway SP, Phillips RR. Morbidity in whooping cough and measles. Archives of Disease in Childhood 64: 1442-1445, 1989

Cusi MG, Rossolini GM, Valensin, Cellesi C, Isanchi A. Serological evidence of reinfection among vaccinees during rubella outbreak. Lancet 336: 1071, 1990

Department of Health. General practice in the NHS. A new contract. Her Majesty's Stationery Office, London, 1989

Department of Health. Immunisation against infectious disease. Her Majesty's Stationery Office, London, 1990

Dyer C. Pertussis and brain damage. British Medical Journal 304: 1652,1992

Edlin BR, Tokars JI, Grieco MH, Crawford JT, Williams J, et al. An outbreak of multidrug-resistant tuberculosis among hospitalised patients with the acquired immunodeficiency syndrome. New England Journal of Medicine 326: 1514-1521, 1992

Expanded Programme on Immunization. Indonesia: outbreak of whooping cough. Weekly Epidemiological Record 59: 26-27, 1984

Ginsberg GM, Tulchinsky TH. Costs and benefits of a second measles innoculation of children in Israel, the West Bank and Gaisa. Journal of Epidemiology and Public Health 44: 274280,1990

Golden GS. Pertussis vaccine and injury to the brain. Journal of Pediatrics 116: 854-861, 1990

Gregg NM. Congenital cataracts following German measles in the mother. Transactions of the Ophthalmological Society 3: 3546, 1941

Griffith AH. Permanent brain damage and pertussis vaccination: is the end of the saga in sight? Vaccine 7: 199-210, 1989

Hinman AP and Kaplan JP. Pertussis and pertussis vaccine. Reanalysis of benefits, risks and costs. Journal of the American Medical Association 254: 1109-1113, 1984

Isaacs $\mathrm{D}$, Menser M. Measles, mumps, rubella, and varicella. In 
Moxon ER (Ed.) Modern vaccines. Current practice and new approaches. Edward Arnold. London, 1990

Jacobs RL, Lowe RS, Lanier BQ. Adverse reactions to tetanus toxoid. Journal of the American Medical Association 247: 4042, 1982

King GE, Markowitz LE, Patriarca PA, Dales LG. Clinical efficacy of measles vaccine during the 1990 measles epidemic. Pediatric Infectious Disease Journal 10: 883-887. 1991

Krantz I, Sekura R. Trollfors B. Taranger J, Zackrisson G, et al. Immunogenicity and safety of a pertussis vaccine composed of pertussis toxin inactivated by hydrogen peroxide in 18- to 23-month old children. Journal of Pediatrics 116: 539-543, 1990

Kulenkampff M, Schwartzman JS, Wilson J. Neurological complications of pertussis innoculation. Archives of Disease in Childhood 49: 46-49, 1974

Lambert HP. The enigma of pertussis. Journal of the Royal College of Physicians of London 19: 67-71, 1985

Leese B, Bosanquet $\mathrm{N}$. Immunization in the UK: policy review and future economic options. Vaccine 10: 491-499, 1992

Lindquist JM. Plotkin SA. Shaw L, Gilden RV. Williams ML. Congenital rubella syndrome as a systematic infection - studies of affected infants born in Philadelphia, U.S.A. British Medical Journal 2: 1401-1406, 1965

Long SS, Deforest A. Smith DG, Laisaro C, Wassilak SGF. Longitudinal study of adverse reactions following diphtheria-tetanus-pertussis vaccine in infancy. Pediatrics 85: 294-302, 1990

Mast EE. Berg JL, Hanrahan LP, Wassell JT, Davis JP. Risk factors for measles in a previously vaccinated population and costeffectiveness of revaccination policies. Journal of the American Medical Association 264: 2529-2538, 1990

Maxwell S. Surveillance of pertussis in Britain. Communicable Disease Report 34: 3-4, 1989

McConnell WWM, Tohani VK. Measles in the Southern Health Board - implications for resources. British Medical Journal 289: 293-296, 1984

McDonald JC, Moore DL. Quennec P. Clinical and epidemiologic features of mumps meningoencephalitis and possible vaccine-related disease. Pediatric Infectious Disease Journal 8: 751. 55, 1989

Medical Research Council. Vaccination against whooping cough. The final report to the Whooping Cough Immunisation Committee. British Medical Journal 1: 994-1000, 1959

Miller E. Rubella reinfection. Archives of Disease in Childhood 65: 820-821, 1990

Miller E. Waight PA, Vurdien JE, White JM, Jones G. Rubella surveillance to December 1990: a joint report from the PHLS and national congenital rubella surveillance programme. Communicable Disease Report 1: R33-R41, 1991

Morgan GM. An outbreak of measles in a London school. Communicable Disease Report 37: 3-4, 1986

Morley DC, Woollard M. Martin MH. Whooping cough in $\mathrm{Ni}$ gerian children. Tropical and Geographical Medicine 18: 169. 182, 1966

Muller AS, Leeuwenburg J, Pratt DS. Pertussis: epidemiology and control. Bulietin of the World Health Organization 64: 321331, 1986

Nassau RD. The costs of preventing measles. Journal of the American Medical Association 267: 655-656. 1992

National Vaccine Advisory Committee. The measles epidemic. The problems, barriers and recommendations. Journal of the American Medical Association 266: 1547-1552, 1991

Nazareth B, Slack MPE, Howard AJ, Wright PA, Begg NT. A survey of invasive Haemophilus influenzae infections. Communicable Disease Report 2: R13-R16, 1992

Nicoll A. Elliman D. Begg NT. Immunisation: causes of failure and strategies and tactics for success. British Medical Journal 299: 808-812, 1989

Noble GR, Bernier RH, Hardegree MC, Hainman AR, Klein D, et al. Acellular and whole cell pertussis vaccines in Japan: report of a visit by US scientist. Journal of the American Medical Association 257: 1351-1356, 1987

Owens CS, Espino RT. Rubella in Panama: still a problem. Paediatric Infectious Disease Journal 8: 110-115, 1989

Palmer SR. Vaccine efficacy and control measures in pertussis. Archives of Disease in Childhood 66: 854-857, 1991

Ramsey MEB, Reo M, Begg NT. Symptoms after accelerated immunisation. British Medical Journal 304: 1534-1536, 1992

Sako W, Treuting WL, Witt NB, Nichamin SJ. Early immunisation against pertussis with alum-precipitated vaccine. Journal of the American Medical Association 127: 379-385, 1945

Sellick JA, Longbine D, Schifeling R, Mylotte JM. Screening hospital employees for measles immunity is more cost effective than blind immunisation. Annals of Internal Medicine 116: 982-984, 1992

Slater PE, Orenstein WA, Morag A, Avni A. Handsher R, et al Poliomyelitis outbreak in Israel in 1988: a report with two commentaries. Lancet 335: 1192-1198, 1990

Sloan D. The costs of preventing measles. Journal of the American Medical Association 267: 656, 1992

Smith MH. National Childhood Vaccine Injury Compensation Act. Pediatrics 82: 264-269, 1988

Springett VH, Sutherland I. BCG vaccination of school children in England and Wales. Thorax 45: 83-88, 1990

Velimirovic B. Social, economic and psychological impacts of childhood diseases subject to immunisation. Infection 19: 237241, 1991

Ẇentz KR, Marcuse EK. Diphtheria-tetanus-pertussis vaccine and serious neurologic illness: an updated review of the epidemiological evidence Pediatrics 87: 187-197, 1991

White SM, Hobday SJ, Begg WT. COVER (cover for vaccination evaluated rapidly): 20 , Communicable Disease Report $2 . \mathrm{Re}-$ view No. 1, R12, January 1992

Correspondence and reprints: Dr S.P. Conway, Consultant in Paediatrics and Infectious Diseases. Seacroft Hospital, York Road. Leeds LS14 6UH, England. 